\title{
COMPREENSÃO DE LEITURA E CONSCIÊNCIA MORFOLÓGICA NO ENSINO FUNDAMENTAL I
}

\author{
Adriana Satico Ferraz \\ Universidade São Francisco, Campus Swift, Campinas/SP \\ Acácia Aparecida Angeli dos Santos \\ Universidade São Francisco, Campus Swift, Campinas/SP
}

\begin{abstract}
Resumo
A compreensão de leitura e a consciência morfológica são habilidades que contribuem para o processo de ensino-aprendizagem. O objetivo do presente estudo foi investigar a proficiência em compreensão de leitura de 70 alunos ( $2^{\circ}$ ao $5^{\circ}$ ano) de uma escola pública paulista e verificar as diferenças de desempenho e as correlações existentes entre esta habilidade e a consciência morfológica. Os instrumentos utilizados foram dois testes de Cloze e as Tarefas de Avaliação da Consciência Morfológica. Os resultados indicaram aumento crescente em compreensão de leitura e consciência morfológica, conforme o avanço dos anos escolares. No $2^{\circ}$ e 30 ano, os alunos obtiveram maiores escores na consciência morfológica derivacional e no $4^{\circ}$ e $5^{\circ}$ ano na flexional. Verificaram-se correlações estatisticamente significativas entre essas habilidades apenas no $3^{\circ}$ e $5^{\circ}$ ano. Sugere-se a continuidade nas investigações sobre o papel da consciência morfológica para o desenvolvimento da compreensão de leitura. Palavras-chave: habilidade linguística; habilidade metalinguística; ensino básico; avaliação psicoeducacional.
\end{abstract}

\section{READING COMPREHENSION AND MORFOLOGICAL AWARENESS IN ELEMENTARY SCHOOL}

\begin{abstract}
Reading comprehension and morphological awareness are skills that contribute to the teaching and learning process. The present study aimed to investigate the reading comprehension proficiency of 70 students (2nd to 5 th grades) of a public school in São Paulo and verify the differences in performance and correlations between this skill and the morphological awareness. The instruments were two Cloze tests and the Morphological Consciousness Assessment Tasks. The results indicated an increase in reading comprehension and morphological awareness, with grade level progression. In the 2nd and 3rd grade the students obtained higher scores in the derivational morphological awareness and in the 4th and 5th grade in the flexional. There were statistically significant correlations between these abilities only in the 3rd and 5th grade. It is suggested continuity in the investigations about the role of morphological awareness for the development of reading comprehension.
\end{abstract}

Keywords: linguistic ability; metalinguistic ability; basic education; psychoeducational evaluation. 


\title{
COMPRENSIÓN DE LECTURA Y CONCIENCIA MORFOLÓGICA EN LA ENSEÑANZA FUNDAMENTAL
}

\begin{abstract}
Resumen
Debido a la importancia del lenguaje y las habilidades metalingüísticas para el proceso de aprendizaje, este estudio investigó la competencia de los estudiantes de educación básica en comprensión de lectura. También se verificaron las diferencias de rendimiento en la comprensión lectora y la conciencia morfológica y las correlaciones existentes entre estas habilidades. Se evaluaron 70 alumnos ( $2^{\circ}$ al $5^{\circ}$ año) de una escuela publica en São Paulo. Los instrumentos utilizados fueron: prueba de Cloze y Tareas de Evaluación de la Conciencia Morfológica. Los resultados indicaron un aumento creciente en comprensión de lectura y conciencia morfológica, conforme el avance de los años escolares. En el 20 y 30 año los alumnos obtuvieron mayores escores en la conciencia morfológica derivativa y en el $4^{\circ}$ y $5^{\circ}$ año en la flexional. Las correlaciones entre estas habilidades fueron estadísticamente significativas entre estas habilidades solo en el $3^{\circ}$ y $5^{\circ}$ año. Se sugiere la continuidad en las investigaciones sobre el papel de la conciencia morfológica para el desarrollo de la comprensión de la lectura.

Palabras clave: habilidad lingüística; habilidad metalingüística; enseñanza básica; evaluación psicoeducativa.
\end{abstract}

\section{INTRODUÇÃO}

A compreensão de leitura caracteriza-se como uma habilidade linguística que envolve a interação de diversos componentes que possibilitam o entendimento do material escrito e da linguagem falada. Dentre esses componentes, se destacam os processos cognitivos básicos ( $p$. ex., memória de trabalho e memória de longo prazo); a participação de outras habilidades linguísticas e metalinguísticas na decodificação/codificação e no reconhecimento de palavras ( $p$. ex., consciências fonológica e morfológica, respectivamente); bem como os processos superiores, relativos às análises semântica e sintática, a elaboração de inferências e a integração do conteúdo apresentado no texto com o conhecimento prévio do leitor (Kintsch \& Rawson, 2013).

Considerando o processo de ensino e aprendizagem, é imprescindível que o aluno compreenda aquilo que lê, uma vez que esta habilidade linguística está ligada ao bom rendimento do aluno na escola, sobretudo nos primeiros anos escolares. Uma vez bem desenvolvida, tende a favorecer o aprendizado dos diversos conteúdos ensinados na escola (Ferraz, Santos, \& Cantalice, 2019; Oliveira, Santos, \& Rosa, 2016). Além do inegável auxílio à instrução formal, a compreensão de leitura também pode proporcionar ao aluno momentos de diversão e lazer por meio da leitura recreativa (material não-didático como gibis e revistas) (Baptista, Freitas Junior, Peçanha, Soares, \& Mettrau, 2016).

Vale salientar, ainda, a importância da compreensão de leitura para o desenvolvimento da consciência crítica no aluno, indispensável ao exercício da cidadania. À medida que ele compreende seus direitos e deveres, poderá assumir um posicionamento mais ativo e autônomo na sociedade (Gilabert, Martínez, \& Vidal-Abarca, 2005). Estes aspectos justificam a relevância de avaliá-la no início 
da escolarização, pois a identificação de déficits na compreensão de leitura pode auxiliar o estabelecimento de medidas preventivas/remediativas (Ferraz et al., 2019; Oliveira et al., 2016). Um meio de se aprofundar nos aspectos envolvidos no desenvolvimento da compreensão de leitura - e que se configura como o objetivo principal do presente estudo - é investigar a sua associação com outras habilidades, como é o caso da consciência morfológica.

A consciência morfológica é uma habilidade metalinguística ligada à reflexão e manipulação deliberada dos morfemas - menores unidades linguísticas dotadas de sentido que compõem as palavras, e das regras de formação de palavras ou pseudopalavras (palavras inventadas). Os morfemas se dividem em raiz (morfema lexical), que expressa o significado básico da palavra, e em afixos, que acompanham a raiz. Os afixos são divididos em prefixos - morfemas adicionados antes da raiz e os sufixos - morfemas acrescidos após a raiz (Guimarães, Paula, Mota, \& Barbosa, 2014; Laroca, 2005). Mediante as exigências das regras ortográficas de cada língua os morfemas são classificados em derivacional e flexional. A consciência morfológica derivacional possui uma função sintático-lexical - adição de prefixos e sufixos que conferem o sentido/significado das palavras e pseudopalavras. Por sua vez, a consciência morfológica flexional se refere à natureza morfossintática das palavras e se pauta somente na adição de sufixos, conforme as regras de concordância nominal e verbal relativas ao gênero (masculino/feminino), grau (diminutivo/aumentativo), número (singular/plural), o tempo verbal, dentre outros (Gilbert, Goodwin, Compton, \& Kearns, 2014; Guimarães \& Mota, 2016; Guimarães et al., 2014).

A contribuição da consciência morfológica para a compreensão de leitura se expressa por meio da apresentação de pistas semânticas que ampliam o conhecimento semântico/lexical do aluno. Devido a sua característica de agilizar a recuperação do significado das palavras, a consciência morfológica tende a favorecer a fluência da leitura e a auxiliar a construção de sentidos daquilo que é lido nos processos de elaboração de inferências e de interpretação do texto (Guimarães et al., 2014; Kruk \& Bergman, 2013; Silva \& Martins-Reis, 2017). A associação entre a consciência morfológica e a compreensão de leitura tende a variar conforme as especificidades de cada língua. Na língua inglesa, por exemplo, a contribuição da consciência morfológica para a leitura aparenta ser maior, visto que um grande número de palavras possui a ortografia irregular e, portanto, estão ligadas aos aspectos morfológicos (Krug \& Bergman, 2013). Em contrapartida, no espanhol a morfologia das palavras apresenta uma relação menor com essa habilidade metalinguística, pois a língua espanhola requer maior ênfase na decodificação dos símbolos gráficos durante a leitura, o que mobiliza mais os aspectos fonológicos - correspondência entre letra e som (Hagen, Miranda, \& Mota, 2011). 
Por sua vez, na língua portuguesa identificam-se palavras baseadas em uma ortografia centralizada na codificação/decodificação (correspondência grafofonêmica), assim como vocábulos que se estruturam em uma ortografia irregular. Estudos nacionais e estrangeiros com alunos do ensino básico apresentam resultados heterogêneos quanto à contribuição da consciência morfológica para a compreensão de leitura. Isto porque os seus resultados indicam que esta habilidade metalinguística aparece ligada tanto de forma direta como indireta com a compreensão do texto (Guimarães \& Mota, 2016; Guimarães et al., 2014; Kruk \& Bergman, 2013; Lúcio, Lima, Jesuíno, \& Rueda, 2018).

Nos estudos desenvolvidos por Guimarães et al. (2014) e Lúcio et al. (2018), com alunos de escolas públicas paranaenses, os autores identificaram associações entre as consciências morfológica derivacional e flexional e a compreensão de leitura tanto em termos de correlação como de predição. Congruente à esses resultados, Gaiolas e Martins (2017), em estudo longitudinal com alunos em fase de alfabetização no português europeu, averiguaram um aumento na contribuição da consciência morfológica para a leitura do $1^{0}$ para o $2^{\circ}$ ano do Ensino Básico, sendo esta habilidade metalinguística prevalente nos bons leitores.

Por sua vez, Kruk e Bergman (2013) identificaram, em uma amostra de alunos canadenses do Elementary School (equivalente ao Ensino Fundamental I brasileiro), que a consciência morfológica se mostrou preditora da compreensão de leitura de palavras isoladas, especificamente no auxílio da identificação do significado das palavras e das sentenças, bem como a disposição destas nas sentenças. Diferentemente, ao avaliarem alunos de uma escola pública carioca, Guimarães e Mota (2016) verificaram que os índices de regressão entre estas habilidades não apresentaram significância estatística. Todavia, a consciência morfológica derivacional foi capaz de predizer a precisão de leitura mesmo com o controle da idade, da inteligência não verbal e verbal e da consciência fonológica. A disparidade destes resultados possivelmente se deve à alternância das habilidades metalinguísticas e dos componentes cognitivos ligados à compreensão de leitura que se modificam ao longo da escolarização, em consonância com o nível de complexidade do texto e devido às diferenciações estruturais do material escrito em diferentes gêneros textuais (Coelho \& Correa, 2017; Cunha \& Santos, 2019; Santos, Ferraz, \& Rueda, 2018).

É que no decorrer do Ensino Fundamental I que os alunos adquirem a habilidade de compreender aquilo que leem e ouvem. Esta compreensão é identificada quando há atribuição de significados e uma noção global do material lido, proveniente da leitura autônoma de conteúdos e gêneros textuais compatíveis com esse nível de ensino (Brasil, 2018; Santos \& Fernandes, 2016). O esclarecimento sobre o quanto a consciência morfológica está associada à compreensão de leitura poderá indicar o quanto a aplicação de atividades 
relacionadas a ela funciona como forma de desenvolver sua proficiência. Aliás, há defesa da ideia de que as atividades pedagógicas devem estimular as habilidades metalinguísticas, dentre elas a consciência morfológica (Brasil, 2018; Oliveira \& Justi, 2017). Pesquisas indicam que as habilidades de compreensão de leitura e consciência morfológica apresentam uma melhora gradativa ao longo do Ensino Fundamental I, (Cunha \& Capellini, 2018; Guimarães, \& Mota, 2016; Guimarães et al., 2014), e que, de forma geral, as habilidades linguísticas e metalinguísticas se desenvolvem mutuamente (Santos et al., 2018).

Com base nas acepções teóricas e empíricas mencionadas, o presente estudo teve por objetivo analisar o nível de proficiência dos alunos em compreensão de leitura. A análise foi guiada pela hipótese de que os alunos do 50 ano demonstrariam maior habilidade em compreender o que leem, quando comparados aos alunos dos anos imediatamente anteriores (40 e $3^{\circ}$ anos). Também, fez parte dos objetivos desta pesquisa, verificar as diferenças de desempenho nas consciências morfológica flexional e derivacional em razão dos grupos de baixo, médio e alto desempenho em compreensão de leitura. A hipótese inicial levantada foi a de que os alunos com alto desempenho em compreensão de leitura apresentariam maior habilidade em consciência morfológica, sendo que o oposto ocorreria com os alunos classificados por seu baixo desempenho em compreensão de leitura. Por último, verificaram-se as correlações existentes entre a consciência morfológica e a compreensão de leitura considerando o ano escolar. Conjecturou-se que estas correlações seriam positivas e de fraca a moderada magnitude, visto que não são as únicas habilidades responsáveis pela compreensão de leitura.

\section{MÉTODO}

Delineamento do estudo: quantitativo - comparação de grupos e correlacional.

\section{Participantes}

A amostra de pesquisa configura-se como de conveniência, composta de 70 alunos do Ensino Fundamental I de uma escola municipal localizada no interior do estado de São Paulo. Participaram alunos do $2^{\circ}$ ano $(n=14), 3^{\circ}(n=$ $24) ; 4^{\circ}(n=19)$ e $5^{\circ}$ ano $(n=13)$, com idades entre sete a 10 anos $(M=8,36$; $D P=1,06)$. A maioria dos alunos era do sexo feminino $(n=40 ; 57,1 \%)$.

\section{Instrumentos}

Teste de Cloze, "A princesa e o fantasma" e "Uma vingança infeliz" (Santos, 2005).

Ambos os textos apresentavam aproximadamente 250 palavras e 15 lacunas. Para respondê-los o aluno foi orientado a realizar uma primeira leitura 
silenciosa e, em seguida, completar as lacunas com palavras que conferissem um sentido aos textos. A correção adotada nos dois testes foi a literal, sendo contabilizado como acerto somente a palavra escrita corretamente pelo aluno. Ademais, foram somadas as pontuações destes testes (Cloze total), cuja consistência interna (coeficiente alpha) foi de $a=0,90$, considerado satisfatório. Assim, a pontuação mínima foi de 0 e a máxima de 30 pontos. Ambos os textos de Cloze possuem evidências de validade convergente com a escrita (Santos \& Monteiro, 2016), evidência de validade baseada em construtos relacionados consciência fonológica (Suehiro \& Santos, 2015), e evidência de validade de critério concorrente para o ano escolar (Mota \& Santos, 2014), além de estimativas de fidedignidade (Santos, 2005).

Tarefas de Avaliação da Consciência Morfológica (TCM - Mota \& Brilhante, 2012).

Este instrumento consiste em duas subescalas. A primeira, denominada de Analogia Derivacional, aquilata a consciência morfológica derivacional por meio de 17 itens. A segunda, nomeada de Analogia Flexional, afere a consciência morfológica flexional e possuí 19 itens. As TCMs são aplicadas em alunos do Ensino Fundamental I, individualmente e sem tempo máximo para sua realização. Para responder $\mathrm{O}$ instrumento $\mathrm{O}$ aluno é orientado a realizar analogias, sob a lógica de "A está para B, assim como B está para C". $\mathrm{Na}$ correção das TCMs atribui-se 1 ponto para cada acerto e 0 para o erro. Como as subescalas possuem um número de itens diferentes, para o presente estudo calcularam-se as porcentagens para comparação de suas médias. No tocante as suas propriedades psicométricas, a TCM Derivacional apresentou $a=0,67$ e $a$ TCM Flexional, $a=0,63$ (Mota et al., 2013). Na amostra do presente estudo as escalas apresentaram índices de confiabilidade satisfatórios (coeficiente alpha) TCM Derivacional, $a=0,77$, e TCM Flexional, $a=0,86$.

\section{Procedimentos de coleta de dados}

Inicialmente a pesquisa foi aprovada pelo Comitê de Ética da Universidade o qual está vinculada, sob o parecer (CAAE no 48390715.6.0000.5514). A coleta de dados seguiu todos os procedimentos éticos estipulados pelo Conselho Nacional de Saúde - Resolução CNS 466/12 (Brasil, 2012). Após a recolha do Termo de Consentimento Livre e Esclarecido assinado por um dos pais/responsável pelo aluno, a coleta de dados ocorreu em duas etapas, durante o período de aula. A primeira etapa se deu de forma coletiva, em sala de aula, com a aplicação dos dois testes de Cloze (tempo médio de 20 minutos). A segunda etapa aconteceu individualmente, com a aplicação das TCMs, em uma sala reservada pela escola (tempo médio de aplicação: 10 minutos). O período de duração entre a coleta coletiva e individual foi de duas semanas. 
Procedimentos de análise de dados

Os resultados foram analisados por meio do software Statistical Package for Social Sciences (SPSS) - versão 22. Confirmou-se a distribuição da normalidade dos dados por meio do teste Shapiro-Wilk ( $p>0,05$ ). Realizaram-se análises descritivas e de frequência para a caracterização da amostra, identificação das médias e desvios-padrão dos instrumentos e distribuição dos alunos nos grupos de desempenho no Cloze Total. Estes grupos foram formados por meio da análise de quartis. Utilizaram-se as análises paramétricas - análise de variância ANOVA e o teste $t$ de Student para a comparação de grupos, e a análise de correlação $r$ de Pearson - classificação das magnitudes das correlações foram baseadas em Dancey e Ready (2013) - 0,1 a 0,3 (fraca), 0,4 a 0,6 (moderada) e 0,7 a 1,0 (alta). A análise de confiabilidade pautou-se no alfa maior ou igual a 0,70 como índice satisfatório (Urbina, 2007).

\section{RESULTADOS}

Primeiramente, formaram-se três grupos com base no desempenho dos alunos em compreensão de leitura, considerando o ponto de corte dos quartis dos acertos no teste de Cloze total - G1, pontuações baixas, de 0 a 4 pontos; G2, pontuações intermediárias, de 5 a 13 pontos; e G3, pontuações altas, de 14 a 21 pontos. A Tabela 1 exibe a distribuição desses grupos por ano escolar e o número de alunos distribuídos em cada grupo.

Tabela 1.

Estatística descritiva da distribuição dos grupos de desempenho em compreensão de leitura por ano escolar

\begin{tabular}{|c|c|c|c|}
\hline \multicolumn{2}{|c|}{ Ano Escolar } & $f(n)$ & $\%(n)$ \\
\hline \multirow{3}{*}{20 ano } & G1 & 9 & 64,3 \\
\hline & $\mathrm{G} 2$ & 5 & 35,7 \\
\hline & $N$ & 14 & 100,0 \\
\hline \multirow{4}{*}{30 ano } & $\mathrm{G} 1$ & 7 & 29,2 \\
\hline & $\mathrm{G} 2$ & 14 & 58,3 \\
\hline & G3 & 3 & 12,5 \\
\hline & $N$ & 24 & 100,0 \\
\hline \multirow{4}{*}{$4^{\circ}$ ano } & $\mathrm{G} 1$ & 1 & 5,3 \\
\hline & G2 & 12 & 63,2 \\
\hline & G3 & 6 & 31,6 \\
\hline & $N$ & 19 & 100,0 \\
\hline \multirow{4}{*}{$5^{\circ}$ ano } & $\mathrm{G} 1$ & 1 & 7,7 \\
\hline & G2 & 5 & 38,5 \\
\hline & G3 & 7 & 53,8 \\
\hline & $N$ & 13 & 100,0 \\
\hline
\end{tabular}


A análise de variância ANOVA acrescida da prova post hoc de Tukey foram aplicadas no $30,4^{\circ}$ e $5^{\circ}$ ano a fim de averiguar a existência de diferenças no Cloze total nos três grupos de desempenho. Identificaram-se diferenças estatisticamente significativas para todos os anos escolares: $3^{\circ}$ ano, $F(2,21)=$ 71,$143 ; p<0,01 ; 4^{\circ}$ ano, $F(2,16)=27,735 ; p<0,01$ e $5^{\circ}$ ano, $F(2,10)=$ 25,$352 ; p<0,01$. Só foi possível identificar a diferenciação dos subgrupos de desempenho em compreensão de leitura nos alunos do $3^{\circ}$ ano $(\mathrm{G} 1, M=1,43$; $\mathrm{G} 2, M=9,14 ; \mathrm{G} 3, M=16)$, pois, conforme é reportado na Tabela 1 , no 40 e $5^{\circ}$ ano, devido a presença de apenas um caso no G1, não foi possível executar a prova post hoc de Tukey. No $2^{\circ}$ ano, os alunos se agruparam em apenas dois grupos de desempenho no Cloze total (G1 e G2), portanto aplicou-se o teste $t$ de Student ( $\mathrm{G} 1, M=1,00 ; \mathrm{G} 2, M=6,60 ; t=-6,036 ; p<0,01)$. Os resultados da ANOVA e do teste $t$ de Student evidenciaram a progressão dos acertos no Cloze total ao longo dos anos escolares. Isto também pode ser observado na Tabela 1 , que mostra o aumento do número de alunos do $3^{\circ}$ ao $5^{\circ}$ ano alocados no $\mathrm{G} 3$. Na Tabela 2 são apresentados os resultados das diferenças de desempenho nas consciências morfológica derivacional e flexional em face dos grupos de desempenho em compreensão de leitura.

Tabela 2.

Análise de variância ANOVA e prova post hoc de Tukey para as consciências morfológica derivacional e flexional e os grupos de desempenho em compreensão de leitura

\begin{tabular}{|c|c|c|c|c|c|}
\hline \multirow{2}{*}{ TCMs } & \multirow{2}{*}{$F^{*}$} & \multirow[b]{2}{*}{ Grupos** } & \multicolumn{3}{|c|}{ Subgrupos } \\
\hline & & & $N$ & 1 & 2 \\
\hline & & G1 & 16 & 5,56 & \\
\hline \multirow[t]{3}{*}{ Derivacional } & 10,377 & $\mathrm{G} 2$ & 34 & & 8,94 \\
\hline & $p<0,01$ & G3 & 15 & & 10,40 \\
\hline & & $P$ & & 1 & 0,32 \\
\hline \multirow{4}{*}{ Flexional } & & G1 & 16 & 5,19 & \\
\hline & 22,525 & $\mathrm{G} 2$ & 34 & & 10,82 \\
\hline & $p<0,01$ & G3 & 15 & & 13,53 \\
\hline & & $P$ & & 1 & 0,06 \\
\hline
\end{tabular}

Nota. *para todas as comparações, $g l=2 ; * *$ formados pelo desempenho em compreensão de leitura

Conforme sugerem as médias de desempenho em consciência morfológica exibidas na Tabela 2, o G3 e o G2 que englobam alunos com maior nível de compreensão de leitura, possuem maior habilidade de manipulação dos aspectos morfológicos das palavras do que os alunos do G1. Observa-se, também na Tabela 2, uma diferenciação de desempenho nas consciências morfológica derivacional e flexional, de acordo com a classificação do aluno nos grupos de desempenho em compreensão de leitura. Os alunos do G1 (baixo desempenho 
em compreensão de leitura) utilizaram-se mais da consciência morfológica derivacional $(32,71 \%)$ do que a consciência morfológica flexional $(27,32 \%)$. 0 contrário foi observado nos alunos do G3 (melhor desempenho em compreensão de leitura), em que os alunos recorreram mais ao uso da consciência morfológica flexional $(71,21 \%)$ do que a consciência morfológica derivacional $(61,18 \%)$.

As correlações existentes entre as consciências morfológica derivacional e flexional e a compreensão de leitura também foram analisadas com base no ano escolar. Este resultado é exposto na Tabela 3, juntamente com as médias e desvios-padrão dos instrumentos.

Tabela 3.

Médias, desvios-padrão e coeficientes de correlação $r$ de Pearson entre as consciências morfológica derivacional e flexional e a compreensão de leitura

\begin{tabular}{|c|c|c|c|c|c|c|}
\hline Ano & $\begin{array}{c}\text { Instrumento } \\
\mathrm{S}\end{array}$ & $N$ & $M$ & $D P$ & TCMs & $\begin{array}{l}\text { Cloze } \\
\text { Total }\end{array}$ \\
\hline \multirow[t]{3}{*}{20} & $\begin{array}{c}\text { TCM } \\
\text { Derivacional }\end{array}$ & 14 & 6,86 & 3,61 & \multirow{3}{*}{$\begin{array}{l}\text { Derivacional } \\
\text { Flexional }\end{array}$} & \multirow{3}{*}{$\begin{array}{l}0,20 \\
0,51\end{array}$} \\
\hline & $\begin{array}{l}\text { TCM } \\
\text { Flexional }\end{array}$ & 14 & 5,50 & 3,95 & & \\
\hline & Cloze total & 14 & 3,00 & 3,21 & & \\
\hline \multirow[t]{3}{*}{30} & $\begin{array}{c}\text { TCM } \\
\text { Derivacional }\end{array}$ & 21 & 8,00 & 2,98 & \multirow{3}{*}{$\begin{array}{l}\text { Derivacional } \\
\text { Flexional }\end{array}$} & \multirow{3}{*}{$\begin{array}{l}0,52 * \\
0,57 *\end{array}$} \\
\hline & $\begin{array}{l}\text { TCM } \\
\text { Flexional }\end{array}$ & 21 & 9,14 & 3,84 & & \\
\hline & Cloze total & 24 & 7,75 & 5,05 & & \\
\hline \multirow[t]{3}{*}{40} & $\begin{array}{c}\text { TCM } \\
\text { Derivacional }\end{array}$ & 17 & 9,35 & 3,87 & \multirow{3}{*}{$\begin{array}{l}\text { Derivacional } \\
\text { Flexional }\end{array}$} & \multirow{3}{*}{$\begin{array}{l}0,39 \\
0,18\end{array}$} \\
\hline & $\begin{array}{c}\text { TCM } \\
\text { Flexional }\end{array}$ & 17 & $\begin{array}{c}11,7 \\
1\end{array}$ & 3,48 & & \\
\hline & Cloze total & 19 & $\begin{array}{c}11,8 \\
9\end{array}$ & 5,45 & & \\
\hline \multirow[t]{3}{*}{$\begin{array}{c}50 \\
\text { ano }\end{array}$} & $\begin{array}{c}\text { TCM } \\
\text { Derivacional }\end{array}$ & 13 & 9,69 & 3,30 & \multirow{3}{*}{$\begin{array}{l}\text { Derivacional } \\
\text { Flexional }\end{array}$} & \multirow{3}{*}{$\begin{array}{l}0,57^{*} \\
0,84^{*}\end{array}$} \\
\hline & $\begin{array}{c}\text { TCM } \\
\text { Flexional }\end{array}$ & 13 & $\begin{array}{c}14,3 \\
1\end{array}$ & 2,87 & & \\
\hline & Cloze total & 13 & $\begin{array}{c}13,0 \\
0\end{array}$ & 5,40 & & \\
\hline
\end{tabular}

Nota. *Índices estatisticamente significativos $p<0,01$.

Os índices de correlação $r$ de Pearson reportados na Tabela 3 indicaram que tanto a consciência morfológica derivacional, como a flexional apresentaram correlações estatisticamente significativas com a compreensão de leitura apenas no $3^{\circ}$ e $5^{\circ}$ ano. Estas correlações sugerem que a consciência morfológica se desenvolve simultaneamente à compreensão de leitura e vice-versa nestes anos escolares na amostra aqui estudada. A magnitude destas associações aumentou 
do 30 para o $5^{0}$ ano, em ambos os casos, o que pode estar ligado com os estímulos que os alunos recebem durante a instrução formal, que inclui o próprio desenvolvimento da compreensão de leitura.

\section{DISCUSSÃO}

Em vias de investigar sobre o desempenho dos alunos do Ensino Fundamental I em compreensão de leitura, verificou-se uma melhora nessa habilidade, ao comparar o seu desempenho nos anos iniciais e finais desse ciclo. Em relação aos grupos de desempenho em compreensão de leitura, conjecturase que os alunos do G3 tenderam a apresentar maior nível de proficiência nesta habilidade linguística, o que envolve aspectos como a criticidade e a autonomia. Ao focalizar o G1 e G2, levanta-se a hipótese de que os alunos inseridos nesses grupos ainda não compreendiam grande parte daquilo que liam, possivelmente por não terem desenvolvido ou ainda estarem em processo de aquisição de muitas habilidades que favorecerão o alcance de níveis mais elevados de proficiência em compreensão de leitura, seja de ordem cognitiva (p. ex., memória), ou relacionadas à outras habilidades linguísticas (p. ex., reconhecimento de palavras) e metalinguísticas (p. ex., consciência morfológica e fonológica) (Coelho \& Correa, 2017; Kintch \& Rawson, 2013).

Quanto à diferenciação de desempenho em compreensão de leitura nos anos escolares que compõem o Ensino Fundamental I, é notório que esta habilidade tende a se desenvolver gradativamente no decorrer da escolarização, como resultado do contato do aluno com o processo de aprendizagem (Santos \& Fernandes, 2016). Nesse sentido, é necessário considerar as implicações práticas do desenvolvimento da compreensão de leitura, pois o aluno que apresenta dificuldades nesta habilidade pode se apresentar em desvantagem para aprender e expor os conhecimentos adquiridos durante as aulas, e isso tende a piorar com o avanço dos anos escolares, cujos conteúdos a serem aprendidos tornam-se cada vez mais complexos (Ferraz et al., 2019). Baseado nesta premissa, é esperado que os alunos do $2^{\circ}$ ano, que apresentaram menor habilidade em compreender a leitura, ainda a desenvolva, consoante ao que fora verificado nos demais anos escolares, em que os alunos demonstraram melhor desempenho nesta habilidade linguística. Todavia, convém destacar que alguns alunos do 30 ao $5^{0}$ ano foram alocados nos grupos de baixo e médio desempenho em compreensão de leitura, indicativo de que esta habilidade deve ser continuamente avaliada e estimulada, a fim de se ter um panorama geral sobre o seu desenvolvimento/desempenho.

Os resultados do presente estudo sugerem ainda que, para a amostra avaliada, os alunos que possuíam a habilidade de compreensão de leitura mais desenvolvida apresentaram maiores escores na medida de consciência morfológica flexional, indicativo de maior domínio sobre as regras gramaticais 
que determinam, por exemplo, a formação de palavras substantivas, a conjugação de verbos, dentre outras (Guimarães et al, 2014). Esta habilidade, quando bem desenvolvida passa a ser aplicada de forma generalizada pelo aluno, o que contribui para a leitura de palavras isoladas, assim como a apreensão do seu significado, facilitando a compreensão daquilo que é lido (Guimarães \& Mota, 2016).

Em contrapartida, os alunos com dificuldades de compreensão de leitura pontuaram mais na medida de consciência morfológica derivacional, mas ainda assim ficaram aquém da pontuação máxima possível na TCM derivacional (17 pontos). Isso pode se configurar em um indício da falta de habilidade de manejo deliberado do aspecto derivacional da consciência morfológica. Resultados similares foram encontrados por Guimarães et al. (2014), nos quais alunos dos anos iniciais do Ensino Fundamental I apresentaram maior dificuldade na tarefa de consciência morfológica derivacional, pois diferentemente do que ocorre com a consciência morfológica flexional, esta parte da morfologia não possuí regras muito claras, o que demanda mais tempo para se desenvolver e restringe sua generalização para um número menor de palavras, aumentando as chances de erros quando feita de forma arbitrária. Assim, conjectura-se que principalmente os alunos do $2^{0}$ ano da amostra aqui avaliada, empregaram a consciência morfológica derivacional como uma forma de compensar as suas dificuldades em atividades que exigem o uso da linguagem formal (Gilbert et al., 2014). Essa questão deve ser mais bem investigada em estudos futuros, com a finalidade de analisar se essa suposição se sustenta ou se a dificuldade de manipular a consciência morfológica derivacional provém da falta de estímulos por parte das práticas pedagógicas empregadas em sala de aula e, até mesmo, devido a possíveis dificuldades de aprendizagem.

Verificou-se, ainda, ao comparar o $3^{\circ}$ e o $5^{\circ}$ ano, que a compreensão de leitura e a consciência morfológica se correlacionaram e que a magnitude desta associação aumentou nos anos escolares mais avançados. Estudos que investigaram ambas as habilidades no português brasileiro ainda não apresentam um consenso acerca do papel da consciência morfológica para o desenvolvimento e proficiência da compreensão de leitura. Nestas pesquisas, após o controle da idade, da consciência fonológica e de habilidades cognitivas ( $p$. ex., inteligência não verbal), a consciência morfológica esteve relacionada em nível correlacional e preditivo apenas com a leitura de palavras isoladas (Freitas Junior \& Mota, 2015; Guimarães \& Mota, 2016). Em Kruk e Bergman (2013), foi levantada a hipótese de que a consciência morfológica parece atuar no fornecimento de pistas que estimulam a consciência semântica - recuperação do significado das palavras, e a consciência sintática - organização das frases, parágrafos, dentre outros, o que contribuí primeiramente com a compreensão de palavras isoladas e, por conseguinte, com a compreensão do texto. 
A contribuição das habilidades metalinguísticas também tende a variar de acordo com o tipo do texto (p. ex., narrativo, expositivo), pois as suas especificidades estruturais podem interferir no nível de dificuldade de compreender aquilo que é lido. Nesse sentido, as acepções de Coelho e Correa (2017) são congruentes com os resultados do estudo realizado por Santos et al. (2018), onde as autoras constataram uma correlação de forte magnitude entre a compreensão de leitura e a consciência metatextual, habilidade essa que se caracteriza pela capacidade do aluno de discriminar os diferentes gêneros textuais ( $p$. ex., poesia, texto jornalístico). Essa hipótese é reforçada pela contribuição preditiva da consciência metatextual para a compreensão de leitura identificada por Cunha e Santos (2019).

Ainda no tocante às associações examinadas, chamou a atenção a ausência de significância estatística na correlação entre as consciências morfológica derivacional e flexional e a compreensão de leitura nos alunos do 40 ano, visto que com exceção do $2^{\circ}$ ano, houve um aumento gradativo na magnitude das correlações conforme o avanço dos anos escolares ( $3^{\circ}$ e $5^{\circ}$ ano). Resultado similar ocorreu no estudo de Guimarães et al. (2014) com a tarefa de categorização gramatical. As autoras verificaram que os alunos do 40 ano se sobressaíram nessa tarefa em comparação à turma do $5^{\circ}$ ano, o que levou as autoras a levantarem duas hipóteses a respeito. A primeira se refere ao tipo de conteúdo trabalhado em sala de aula com os alunos dessa faixa escolar, que pode ter dado maior ênfase a outras habilidades e não aquela que fora avaliada. A outra, é a de que o conteúdo avaliado pode ter sido trabalhado nos anos escolares anteriores, mas não houve uma consolidação desta aprendizagem que possibilitasse o seu uso de forma efetiva. Seguindo este mesmo raciocínio, devido ao fato de a presente pesquisa ser de natureza transversal, pode-se supor que nos anos escolares anteriores (ex. $3^{\circ}$ ano), os alunos do $4^{\circ}$ ano talvez não tenham tido contato com atividades voltadas para o desenvolvimento da consciência morfológica ou que não a tenham desenvolvido o suficiente para auxiliá-los a responder o teste de Cloze. Estes aspectos podem ter gerado a descontinuidade nas correlações entre esta habilidade metalinguística e a compreensão de leitura nos diferentes anos escolares do Ensino Fundamental I.

\section{CONSIDERAÇÕES FINAIS}

Ademais, ao discutir os resultados obtidos no presente estudo emergem limitações que devem ser compreendidas e consideradas na agenda de pesquisas futuras que venham a dar continuidade ao estudo das associações entre as habilidades linguísticas e metalinguísticas. Neste sentido, julga-se necessária a ampliação da amostra, tanto em número de participantes, como a inclusão de escolas com outras características e de outros estados brasileiros, como também ampliar a avaliação da consciência morfológica dos alunos mais novos (p. ex. 
educação infantil, $1^{\circ}$ ano) e de alunos do Ensino Fundamental II. Este último aspecto se justifica pela necessidade de conhecer quais os elementos da consciência morfológica o aluno detém, assim que inicia a instrução formal e os aspectos que podem não ter se desenvolvido ao final do segundo ciclo, a fim de auxiliar na revisão e (re)formulação das práticas pedagógicas que envolvem o ensino das regras ortográficas e gramaticais. Em estudos futuros é necessário, também, realizar o controle da consciência fonológica, que pode interferir na compreensão de leitura para além da consciência morfológica, devido às particularidades da língua portuguesa (pautada na correspondência entre letrasom). Adicionalmente, se destaca a verificação da associação e a potencial contribuição da consciência morfológica para outras habilidades metalinguísticas - consciência semântica e sintática.

No tocante ao teste de Cloze, seria interessante verificar em qual medida a habilidade de escrita interfere no desempenho do aluno neste instrumento, dado a correção literal adotada tanto no presente estudo como em outras pesquisas que avaliaram a compreensão de leitura por meio deste recurso (Cunha \& Santos, 2019; Lúcio et al., 2018; Santos \& Ferraz, 2017; Santos et al., 2018). Além disso, seria interessante verificar se a aplicação do teste de Cloze Oral pode funcionar como uma alternativa para eliminar a interferência da escrita, o que serviria também para que este teste fosse aplicado como uma forma de avaliar a compreensão da leitura por via oral.

Em termos práticos, ressalta-se a importância da aplicação de atividades em sala de aula que estimulem o desenvolvimento da consciência morfológica e o desenvolvimento proficiente em compreensão de leitura. Considera-se que o ensino da língua deve ultrapassar o simples ato de decorar. Desse modo, as regras gramaticais e ortográficas podem ser transmitidas ao aluno de forma contextualizada, dando-Ihe a possibilidade de perceber a sua aplicabilidade no seu dia a dia, o que pode vir a contribuir favoravelmente para a formação de leitores que compreendem aquilo que leem e que sentem prazer na prática da leitura.

\section{DECLARAÇÃO DE CONFLITOS DE INTERESSE}

Este é um artigo especial, solicitado pela revista Estudos Interdisciplinares em Psicologia aos membros do seu Conselho Editorial, do qual a prof. Dra. Acácia A. A. dos Santos é membro. No que tange ao conteúdo do trabalho, as autoras informam que não há conflitos de interesse. 


\section{REFERÊNCIAS}

Baptista, R. M., Freitas Junior, P. V., Peçanha, A. P., Soares, A. B., \& Mettrau, M. B. (2016). Práticas de leitura e compreensão de texto no 60 e 70 anos do ensino fundamental. Estudos de Psicologia, 33(1), 173-182.doi: $10.1590 / 1982-027520160001000017$

Brasil, Conselho Nacional de Saúde. (2012). Resolução No 466, de 12 de dezembro de 2012. Recuperado de http://bvsms.saude.gov.br/bvs/saudelegis/cns/2013/res0466 12122012. html

Brasil, Ministério da Educação (2018). Base Nacional Comum Curricular. Recuperado de http://basenacionalcomum.mec.gov.br/images/BNCC_EI_EF_110518_versa ofinal_site.pdf

Coelho, C. L. G., \& Correa, J. (2017). Compreensão de leitura: habilidades cognitivas e tipos de texto. Psico, 48(1), 40-49.

Cunha, V. L. O., \& Capellini, S. A. (2018). Caracterização do desempenho de escolares do $3^{\circ}$ ao $5^{\circ}$ ano do ensino fundamental em compreensão de leitura. Revista CEFAC, 18(4), 941-951. doi: 10.1590/19820216201618421215

Cunha, N. de B., \& Santos, A. A. A. (2019). Avaliação da consciência metatextual e sua predição da compreensão de leitura. Revista Psicologia Teoria e Prática, 21(1), 53-68. doi: 10.5935/1980-6906/psicologia.v21n1p53-68

Dancey, C. P. \& Reidy, J. (2013). Estatística sem matemática para psicólogos. São Paulo: Editora Penso.

Ferraz, A. S., de Cantalice, L. M., \& dos Santos, A. A. A. (2019). Motivação para aprender e compreensão de leitura em alunos do Ensino Fundamental I. Estudos Interdisciplinares em Psicologia, 10(1), 173-189. doi: 10.5433/2236-6407.2019v10n1p173

Freitas Junior, P. V. D., \& Mota, M. M. P. E. D. (2015). So, Morphological Awareness Contributes to Reading in Brazilian Portuguese?. Psico-USF, 20(3), 471-480. doi: 10.1590/1413-82712015200309

Gaiolas, M. S., \& Martins, M. A. (2017). Conhecimento metalinguístico e aprendizagem da leitura e da escrita. Análise Psicológica, 35(2), 117124.doi: 10.14417/ap.1175

Gilbert, J. K., Goodwin, A. P., Compton, D. L., Kearns, D. M. (2014). Multisyllabic word reading as a moderator of morphological awareness and reading comprehension. Journal of Learning Disabilities,47(1):34-43. doi: $10.1177 / 0022219413509966$. 
Gilabert, R., Martínez, G., \& Vidal-Abarca, E. (2005). Some good texts are always better: Text revision to foster inferences of readers with high and low prior background knowledge. Learning and Instruction, 15(1), 45-68. doi: 10.1016/j.learninstruc.2004.12.003

Guimarães, S. B., \&Mota, M. M. P. E. D. (2016). Qual a contribuição da consciência morfológica das crianças na precisão de leitura de palavras e compreensão de texto no português?. Estudos de Psicologia (Natal), 21(3), 239-248.doi: 10.5935/1678-4669.20160023

Guimarães, S. R. K., Paula, F. V., Mota, M. M. P. E., \& Barbosa, V. R. (2014). Consciência morfológica: que papel exerce no desempenho ortográfico e na compreensão de leitura?. Psicologia USP, 25(2), 201-212. doi: 10.1590/0103-6564A20133713

Hagen, V., Miranda, L. C., \& da Mota, M. M. P. E. (2011). Consciência morfológica: um panorama da produção científica em línguas alfabéticas. Revista Psicologia Teoria e Prática, 12(3), 135-148.

Kintsch, W., \& Rawson, K. A. (2013). Compreensão. In M. J. Snowling, \& C. Hulme (Orgs.). A ciência da leitura, (pp. 227-244). Porto Alegre: Penso.

Kruk, R. S., \& Bergman, K. (2013). The reciprocal relations between morphological processes and reading. Journal of Experimental Child Psychology, 114(1), 10-34. doi: 10.1016/j.jecp.2012.09.014

Laroca, M. N. C. (2005). Manual de morfologia do Português. Campinas, SP: Pontes.

Lúcio, P. S., Lima, T. H. D., Jesuíno, A. D. S. A., \& Rueda, F. J. (2018). Compreensão de leitura e consciência morfológica em crianças do ensino fundamental. Estudos Interdisciplinares em Psicologia, 9(3), 112-131. doi: 10.5433/2236-6407.2018v9n3suplp112

Mota, M. M. P. E., \& Brilhante, S. (2012). Tarefas de consciência morfológica. Relatório técnico não publicado. Rio de Janeiro; UERJ.

Mota, M. M. P. E., Lisboa, R., Dias, J., Gontijo, R., Paiva, N., Mansur-Lisboa, S., ... \& dos Santos, A. A. A. (2009). Relação entre consciência morfológica e leitura contextual medida pelo teste de Cloze. Psicologia: Reflexão e Crítica, 22(2), 223-229. doi: 10.1590/S0102-79722009000200008

Mota, M. M. P. E. D., \& Santos, A. A. A. (2014). The Cloze evaluation as a measure of reading ability in primary education. Psicologia Escolar e Educacional, 18(1), 135-142. doi.org/10.1590/S1413-85572014000100014

Oliveira, K. L. D., Boruchovitch, E., \& Santos, A. A. A. D. (2007). Compreensão de leitura em alunos de sétima e oitava séries do ensino fundamental. Psicologia Escolar e Educacional, 11(1), 41-49. doi: $10.1590 /$ S1413-85572007000100005 
Oliveira, B. S. F., \& Justi, F. R. R. (2018). A contribuição da consciência morfológica para a leitura no português brasileiro. Revista Psicologia Teoria e Prática, 19(3), 270-286. doi: 10.5935/1980-6906/psicologia.v19n3p270286

Oliveira, K. L. D., Santos, A. A. A., \& Rosa, M. T. (2016). Compreensão em leitura no ensino fundamental. Psicologia: Ciência e Profissão, 36(3), 546557. doi: 10.1590/1982-3703001172014

Mota, M. M. P. E., Guimarães, S. B., Conti, C., Linhares, T., Rezende, L. B., Amorin, S., ... \& Gumier, A. B. (2013). Diferenças entre o desenvolvimento da morfologia derivacional e flexional no português brasileiro no ensino fundamental. Psicologia: Reflexão e Crítica, 26(4), 730-734. doi: 10.1590/S0102-79722013000400013

Santos, A. A. A. (2005). Evidências e validade de critério para o Teste de Cloze. (Manuscrito não publicado). Programa de Pós-graduação Stricto-Sensu em Psicologia da Universidade São Francisco: Itatiba, SP.

Santos, A. A. A., \& Fernandes, E. S. D. O. (2016). Habilidade de escrita e compreensão de leitura como preditores de desempenho escolar. Psicologia Escolar e Educacional, 20(3), 465-473. doi: 10.1590/21753539201502031013

Santos, A. A. A., \& Ferraz, A. S. (2017). Avaliação de habilidades relacionadas à compreensão de leitura no ensino fundamental. Psico, 48(1), 21-30. doi: 10.15448/1980-8623.2017.1.24376

Santos, A. A. A., Ferraz, A. S., \& Rueda, F. J. M. (2018). Relações entre a Compreensão de Leitura e as Habilidades Metalinguísticas. Psicologia Escolar e Educacional, 22(2), 301-309. doi: 0.1590/2175-35392018026239

Santos, A. A. A., \& Monteiro, R. M. (2016). Validade do Cloze enquanto técnica de avaliação da compreensão de leitura. Estudos Interdisciplinares em Psicologia, 7(2), 86-100.

Silva, A. A. M., \& Martins-Reis, V. D. O. (2017). Influência da consciência morfológica na leitura e na escrita: uma revisão sistemática de literatura. CoDAS, 29(1), 1-8. doi: 10.1590/2317-1782/20172016032

Suehiro, A. C. B.; Santos, A. A. A. (2015). Compreensão de leitura e consciência fonológica: evidências de validade de suas medidas. Estudos de Psicologia (Campinas), 32(2), 201-211. doi: 10.1590/0103-166X2015000200005

Urbina, S. (2007). Fundamentos da testagem psicológica. Porto Alegre, RS: Artes Médicas. 
Sobre as autoras

Adriana Satico Ferraz é psicóloga pela Universidade São Francisco (USF) e Mestre em Psicologia pela USF. Atualmente é Doutoranda em Psicologia pela USF (linha de concentração Avaliação Psicológica e Educacional) com bolsa de pesquisa concedida pela Fundação de Amparo à Pesquisa do Estado de São Paulo (FAPESP). adrianasatico.as@gmail.com

Acácia Aparecida Angeli dos Santos é psicóloga pela Universidade de São Paulo (USP), Mestre em Psicologia Clínica pela Pontifícia Universidade Católica de Campinas e Doutora em Psicologia Escolar e do Desenvolvimento Humano pela USP. Atua como docente no Programa de Pós-graduação Stricto Sensu em Psicologia da Universidade São Francisco. Bolsista Produtividade do CNPq 1A. acacia.santos@usf.edu.br

A contribuição de cada autor pode ser atribuída como se segue: Adriana Satico Ferraz e Acácia Aparecida Angeli dos Santos. contribuíram para a conceitualização, investigação e visualização do artigo; Acácia Aparecida Angeli dos Santos foi responsável pela obtenção de financiamento; Adriana Satico Ferraz fez a redação inicial do artigo (rascunho) e Adriana Satico Ferraz e Acácia Aparecida Angeli dos Santos são os responsáveis pela redação final (revisão e edição).

As autoras agradecem ao Conselho Nacional de Desenvolvimento Científico e Tecnológico (CNPq) pelo financiamento da pesquisa.

Recebido em: 21/08/2019

Revisado em: 30/08/2019

Aceito em: $13 / 09 / 2019$ 